\title{
Coulisses
}

Revue de théâtre

15 | Hiver 1997

Varia

\section{A propos du drame romantique}

Léo Burckart de Gérard de Nerval et Alexandre Dumas à la Comédie-

Française

\section{Philippe Baron}

\section{(2) OpenEdition}

1 Journals

Édition électronique

URL : http://journals.openedition.org/coulisses/5215

DOI : $10.4000 /$ coulisses.5215

ISSN : 2546-9460

\section{Éditeur}

Presses universitaires de Franche-Comté

\section{Édition imprimée}

Date de publication : 1 janvier 1997

Pagination : 72

ISSN : 1150-594X

\section{Référence électronique}

Philippe Baron, «A propos du drame romantique », Coulisses [En ligne], 15 | Hiver 1997, mis en ligne le 26 avril 2019, consulté le 24 septembre 2020. URL : http://journals.openedition.org/coulisses/5215 ; DOI : https://doi.org/10.4000/coulisses.5215

Ce document a été généré automatiquement le 24 septembre 2020.

Coulisses 


\title{
A propos du drame romantique
}

\author{
Léo Burckart de Gérard de Nerval et Alexandre Dumas à la Comédie- \\ Française
}

Philippe Baron

1 La Comédie-Française a eu la bonne idée de monter cette année un drame presque oublié de Gérard de Nerval et Alexandre Dumas, Léo Burckart. Le nom de Nerval auteur dramatique a en effet été éclipsé d'une façon assez injuste par celui de Victor Hugo. Le succès de Musset a contribué lui aussi à l'effacer des mémoires. La collaboration de deux écrivains tels que Nerval et Dumas aurait pu, semble-t-il, retenir davantage l'attention. Ils ont écrit leur pièce en 1838 après un voyage en Allemagne, dans des circonstances assez mal connues. Ils ont pu penser, bien qu'il n'en reste guère de traces dans la pièce, à l'assassinat de Kotzebue par Karl Sand. Ils songent aussi sans doute à Metternich, à Talleyrand, à Thiers, à Guizot, à l'activité des sociétés secrètes en France à leur époque et aux attentats dirigés contre Louis-Philippe.

La pièce qui comprend un prologue et cinq actes, pose la question des rapports de l'intellectuel et du pouvoir. Elle peut, à ce titre, être rapprochée de Lorenzaccio et des Mains sales de Sartre. Elle est située dans l'Allemagne de 1819, où la jeunesse est en effervescence. Le professeur Léo Burckart est un intellectuel qui défend par sa plume des idées libérales. Le prince Frédéric-Auguste le prend comme ministre. Léo Burckart est alors obligé de sacrifier une partie de ses convictions et de maintenir l'ordre. Le drame politique se double d'un drame conjugal finement observé. Sa femme, Marguerite, est en effet malheureuse parce que ses fonctions l'accaparent complètement. Un complot se trame et Franz, le soupirant de Marguerite, est désigné pour abattre Léo Burckart. Il finit par se suicider et Léo Burckart démissionne pour retrouver une vie paisible avec sa femme. La pièce finit bien, mais il est clair que la politique et la vertu sont incompatibles.

2 La mise en scène de Jean-Pierre Vincent, ex-administrateur de la Comédie-Française, sert très bien la pièce. Jean-Pierre Vincent et Jean-Pierre Chambas ont imaginé des décors variés, aux lignes épurées, qui mettent les acteurs en valeur sans les écraser. L'espace presque vide du bureau de Léo Burckart attire le regard sur la table qui est le symbole de son travail. Le jardin de l'acte III, très simple, permet de bien voir le 
château dans lequel passent et repassent les invités. Le décor de l'hôtel à l'acte I est très vivant et le château en ruines de l'acte IV est sinistre à souhait. La distribution est excellente. Andrzej Seweryn est très à l'aise dans le rôle de Léo Burckart. Il a un air tout à fait bourgeois et il est digne, sincère et émouvant. Ceux qui l'ont vu dans Dom Juan, mis en scène par Jacques Lassalle à la même Comédie-Française en 199[?], ne peuvent qu'admirer la souplesse de son talent. Cécile Brune dans le rôle de Marguerite, exprime très bien un amour conjugal blessé. Thierry Hancisse est un Franz romantique et tourmenté. Les étudiants paraissent à la fois chahuteurs et animés d'un amour sincère de la liberté. Les scènes d'ensemble, comme celle de l'hôtel, sont très bien réglées.

La pièce a sans doute plus intéressé qu'emballé, mais le succès n'en a pas moins été fort honorable.

\section{ANNEXES}

\section{Colloque :}

Le festival Terres d'auteurs et le service culturel de l'Université du Havre ont décidé de coréaliser, chaque année, des Rencontres Nationales de Dramaturgie. Cette manifestation sera parrainée par la ville du Havre et fera l'objet d'un travail de préparation par les étudiants du département Carrières sociales (option animateurs socio-culturels de l'I.U.T. du Havre.

Notre but, pour ces rencontres est de réfléchir à différents aspects de la littérature dramatique. Nous avons choisi cette année de promouvoir un colloque sur le drame romantique, qui est aussi le programme de l'épreuve anticipée de Français au baccalauréat. Les rencontres se tiendront le 4 avril à l'Université du Havre (éventuellement aussi le 3 avril).

Contacts : Yoland Simon

Professeur IUT le Havre

Responsable du Festival Terres d'auteurs

9 rue de l'aviation 76600 le Havre

Tél 0235441030

IUT le Havre 0232797100

Carrières sociales 0232797227

IUT fax 0232797171 